\title{
Brothers of women with polycystic ovary syndrome are characterised by impaired glucose tolerance, reduced insulin sensitivity and related metabolic defects
}

\author{
J.-P. Baillargeon • A. C. Carpentier
}

Received: 16 March 2007 / Accepted: 17 August 2007 / Published online: 27 September 2007

(C) Springer-Verlag 2007

\begin{abstract}
Aims/hypothesis Since it has been shown that polycystic ovary syndrome (PCOS) is highly inherited and characterised by insulin resistance, we hypothesised that male siblings of PCOS women would also be insulin resistant. Thus, our aim was to assess insulin sensitivity and metabolic parameters in brothers of women with PCOS and male control individuals.

Methods Seventeen brothers of PCOS women and 28 male control volunteers were assessed with $75 \mathrm{~g}$ OGTTs and euglycaemic-hyperinsulinaemic clamps. PCOS index women were identified using criteria developed at the 1990 National Institutes of Health conference.

Results Brothers and control individuals were similar in terms of BMI, waist circumference, percentage body fat and BP. However, brothers had increased triacylglycerol $(p=0.02)$, plasminogen activator inhibitor-1 (PAI-1; $p=0.02)$, factor VIII $(p=0.02), 2 \mathrm{~h}$ glucose $(p<0.001), \mathrm{AUC}_{\text {glucose }}(p<0.001)$ and $\mathrm{AUC}_{\text {insulin }}(p<0.001)$. Insulin sensitivity was reduced by $38 \%$ in brothers $(p<0.001)$, and this was primarily due to a $65 \%$ decrease in insulin-stimulated non-oxidative carbohydrate metabolism $(p<0.001)$. These differences remained significant after adjustment for age and BMI, except for triacylglycerol, PAI-1 and fasting glucose. The main findings also persisted after excluding individuals with impaired glucose tolerance or diabetic siblings. Significant interactions with BMI status were found for sex hormone-binding globulin, androstenedione, $\mathrm{PAI}-1$ and $\mathrm{AUC}_{\text {insulin, which were }}$
\end{abstract}

J.-P. Baillargeon $(\triangle) \cdot$ A. C. Carpentier

Division of Endocrinology, Department of Medicine,

Université de Sherbrooke,

Sherbrooke, QC, Canada

e-mail: JP.Baillargeon@USherbrooke.ca significantly altered only in obese brothers (vs control individuals).

Conclusions/interpretation Brothers of PCOS women are characterised by decreased insulin sensitivity and glucose tolerance, as well as hypercoagulability, independently of obesity. Therefore, brothers of PCOS women may have inherited the insulin resistance and metabolic syndrome typical of PCOS.

Keywords Impaired glucose tolerance - Insulin resistance · Male siblings $\cdot$ Metabolic syndrome .

Polycystic ovary syndrome

$\begin{array}{ll}\text { Abbreviations } \\ \text { Chox } & \text { Carbohydrate oxidative metabolism } \\ \text { Chnox } & \text { Carbohydrate non-oxidative metabolism } \\ \text { CHUS } & \text { Centre Hospitalier Universitaire de } \\ & \text { Sherbrooke } \\ \text { DHEAS } & \text { dehydroepiandrosterone sulphate } \\ \text { hsCRP } & \text { highly sensitive C-reactive protein } \\ \text { IGT } & \text { impaired glucose tolerance } \\ \text { NCEP-ATP } & \text { National Cholesterol Education Program } \\ \text { III } & \text { Adult Treatment Panel III } \\ \text { PAI-1 } & \text { plasminogen activator inhibitor-1 } \\ \text { PCOS } & \text { polycystic ovary syndrome } \\ \mathrm{SHBG}_{\dot{V} \mathrm{CO}} & \text { sex hormone-binding globulin } \\ \dot{V} \mathrm{O}_{2} & \text { rate of } \mathrm{CO}_{2} \text { production } \\ & \text { rate of } \mathrm{O}_{2} \text { consumption }\end{array}$

\section{Introduction}

Polycystic ovary syndrome (PCOS) is a prevalent disorder defined by hyperandrogenism, chronic anovulation and/or 
polycystic ovaries $[1,2]$. It affects $6-10 \%$ of women of child-bearing age $[3,4]$ and is the most common endocrinopathy in these young women. Moreover, it is associated with an increased risk of developing hypertension, dyslipidaemia, impaired glucose tolerance (IGT) or type 2 diabetes, the metabolic syndrome and cardiovascular diseases $[3,4]$.

Indeed, the prevalence of metabolic syndrome was found to be twice as high in PCOS women compared with the general US population (46 vs 23\%) [5]. The prevalence of glucose intolerance (16-35\%) and type 2 diabetes (2.5$17.7 \%$ ) was also increased in PCOS women compared with normal US women of similar age (7.8 and 1\%, respectively, in NHANES II) [3]. In addition, the prevalence of type 2 diabetes was four times as high in perimenopausal women with a history of PCOS compared with control individuals (32 vs $8 \%$ ) [6].

Increasing evidence supports the central role of insulin resistance and/or compensatory hyperinsulinaemia in the pathogenesis of PCOS [3, 4, 7]. Indeed, obese and lean women with PCOS display insulin resistance independently of BMI [3, 4, 8], and administration of insulin-sensitising drugs such as metformin [3, 4], troglitazone [3, 4], or D-chiro-inositol $[9,10]$ to both obese and lean women with PCOS increases the frequency of ovulation and decreases circulating androgens.

Previous studies have found high incidences of familial clustering of PCOS, suggesting that PCOS may be a genetic disease [11-13]. However, little is known about PCOS genetics and studies have thus far been hindered by the lack of a male phenotype. Some studies have found increased risk of premature male pattern baldness in PCOS families [14-17], but a large study did not confirm this risk [18].

Few studies have assessed the metabolic phenotype of relatives of women with PCOS [13, 19-25], and only four of these assessed brothers [19-22]. These studies showed hyperinsulinaemia or altered indirect indices of insulin resistance in brothers, sisters, mothers or fathers of women with PCOS. Moreover, a recent study found that sisters of PCOS women have an increased prevalence of the metabolic syndrome [24]. However, no previous study has determined insulin sensitivity using the 'gold standard' euglycaemichyperinsulinaemic clamp method in brothers of PCOS women and control participants. Assessment of male siblings is of particular interest because female siblings have been shown to have increased androgen levels, which might cause some degree of insulin resistance.

Therefore, we hypothesised that insulin resistance that characterises PCOS is inherited and thus male siblings of PCOS women have higher a degree of insulin resistance and markers of the insulin resistance syndrome. To test this hypothesis, brothers of women with PCOS and male control participants unrelated to PCOS women were assessed.

\section{Methods}

Participants Seventeen brothers of women with PCOS and 28 male control participants were recruited. PCOS index women were identified using established criteria $[1,2]$, e.g. oligomenorrhoea (eight or fewer menstrual periods in the preceding year) or confirmed anovulation and hyperandrogenaemia (calculated free testosterone $>50 \mathrm{pmol} / 1$ $[1.4 \mathrm{ng} / \mathrm{dl}])$. All had normal serum prolactin and thyroid function tests. Late-onset congenital adrenal hyperplasia was excluded by a serum $17 \alpha$-hydroxyprogesterone level $<10 \mathrm{nmol} / \mathrm{l}(3.0 \mu \mathrm{g} / \mathrm{l})$ [26]. Pelvic ultrasound was not performed, and so this criterion of the 2003 Rotterdam consensus conference was not considered [1]. All PCOS probands were treated at the Reproductive Endocrinology Clinic of the Centre Hospitalier Universitaire de Sherbrooke (CHUS).

Our control group was a convenient sample of men selected in order to be comparable on average with brothers of women with PCOS for age and BMI. They were recruited from hospital personnel, students at the Université de Sherbrooke or following an advertisement in Sherbrooke city newspapers. No control individual had any first-degree relatives with a known diagnosis of PCOS, or features of PCOS, based on interview.

All participants were in good health, aged between 18 and 40 years, with BMI between 19 and $40 \mathrm{~kg} / \mathrm{m}^{2}$, and had never used insulin-sensitising drugs or medications that affect insulin sensitivity. Control individuals and brothers with type 2 diabetes according to interview, fasting glucose or $75 \mathrm{~g}$ OGTT were excluded. One brother and one control participant were on a lipid-lowering drug (statin), and their lipid profiles were excluded from all analyses. The study was approved by the Human Research Ethics Committee of the CHUS and all participants gave their written informed consent.

Study protocol All procedures were performed at the Centre de Recherche Clinique Etienne-Le Bel of the CHUS. During the first study visit, a complete medical and familial history was recorded and a physical examination was performed, including lean body mass by standing electrical bioimpedance (model no. TBF-300A; Tanita Corporation, Tokyo, Japan). Waist circumference was measured with a flexible tape midway between the last rib and iliac crest, at the end of a normal expiration. BP was recorded following a $5 \mathrm{~min}$ rest period in the sitting position. Fasting blood samples were drawn for determination of plasma steroids, metabolic evaluation and safety blood tests (complete blood count, electrolytes, creatinine, 
liver function tests, calcium, phosphorus). At approximately 09:00 hours, a standard OGTT was performed by administering $75 \mathrm{~g}$ glucose orally and the AUCs for glucose and insulin response curves were calculated by the trapezoidal rule using absolute values. Finally, participants were instructed to maintain an isocaloric standard diet for $48 \mathrm{~h}$ prior to the euglycaemic-hyperinsulinaemic clamp [27].

At least 2 days later, after a $12 \mathrm{~h}$ overnight fast, insulin sensitivity was directly determined using the euglycaemichyperinsulinaemic clamp as previously described $[28,29]$. An insulin dose of $40 \mathrm{mU} \mathrm{m}^{-2} \mathrm{~min}^{-1}$ was used and total-body carbohydrate metabolism ( $M$ value, $\mu \mathrm{mol} \mathrm{kg}{ }^{-1} \min ^{-1}$ ) was calculated as follows: glucose infusion rate during the last $30 \mathrm{~min}$ of the clamp ( $\mu \mathrm{mol} / \mathrm{min}$ ) divided by the participant's weight $(\mathrm{kg})$ [28]. Finally, in an unselected subgroup of participants, the rates of $\mathrm{O}_{2}$ consumption $\dot{V} \mathrm{O}_{2}$ and $\mathrm{CO}_{2}$ production $\dot{V} \mathrm{CO}_{2}$ were measured during a 40 min baseline period and during the last $40 \mathrm{~min}$ of the clamp to determine total-body carbohydrate oxidation by indirect calorimetry (Vmax29n; Sensormedics, Yorba Linda, CA, USA). Basal and insulin-stimulated total-body oxidative carbohydrate metabolisms (CHox, $\mu \mathrm{mol} \mathrm{kg}{ }^{-1} \mathrm{~min}^{-1}$ ) were calculated as follows: $\left(25.196 \times \dot{V} \mathrm{CO}_{2} /\right.$ weight $)-\left(17.749 \times \dot{V} \mathrm{O}_{2} /\right.$ weight $)-$ $\left(0.21349 \times 1.047 \times 10^{-4} \times\right.$ weight $)$; and insulin-stimulated total-body non-oxidative carbohydrate metabolism (CHnox, $\mu \mathrm{mol} \mathrm{kg}{ }^{-1} \mathrm{~min}^{-1}$ ), as follows: $M$ value-CHox $[27,30]$.

Assays Blood samples were assayed by the biochemistry core laboratory of the CHUS, except for highly sensitive C-reactive protein (hsCRP) that was assayed in the laboratory of J.-P. Baillargeon at Université de Sherbrooke, Sherbrooke, QC, Canada. Total testosterone, androstenedione and $17 \alpha$-hydroxyprogesterone levels were assayed by RIA (Diagnostic Systems Laboratories, Webster, TX, USA). Sex-hormone binding globulin (SHBG) was assayed by IRMA and dehydroepiandrosterone sulphate (DHEAS) and insulin by RIA (Diagnostic Products, Los Angeles, CA, USA). Serum free testosterone was calculated by the method of Sodergard et al. using a serum albumin concentration of $40 \mathrm{~g} / 1(4.0 \mathrm{~g} / \mathrm{dl})$ [31]. Oestradiol, progesterone, folliclestimulating hormone, luteinising hormone, thyrotrophin and prolactin were measured by chemiluminescent immunoassay on an automated ADVIA Centaur analyser (Bayer HealthCare, Toronto, ON, Canada).

Glucose was assayed using a bedside Beckman Coulter Glucose Analyzer II (Beckman Coulter Canada, Mississauga, ON, Canada). Total cholesterol, triacylglycerol and HDLcholesterol were measured by chemiluminescent immunoassay on an automated Vitros analyser (Ortho-Clinical Diagnostics, Missisauga, ON, Canada). LDL-cholesterol was calculated using the Friedewald equation [32]. Fibrinogen was assayed by the modified Clauss technique using BCS kits (Behring Coagulation System, Netwark, DE,
USA). Plasminogen activator inhibitor-1 (PAI-1) and factor VIII levels were determined by ELISA (Diagnostica Stago, Asnières-sur-Seine, France). Factor VIII is a clotting factor of the intrinsic coagulation cascade that has been associated with a prothrombotic state and the metabolic syndrome [33, 34]. hsCRP was measured by ELISA (Alpha Diagnostic International, San Antonio, TX, USA). Inter- and intraassay CV values were $<7.5 \%$ for insulin, $<5 \%$ for hsCRP, $<10 \%$ for total testosterone and $<8.5 \%$ for all other steroid hormones.

Statistical analyses Results not normally distributed were $\log _{\mathrm{e}}$-transformed in order to normalise their distribution for all statistical analyses, and are reported herein backtransformed in their original units (geometric means with interquartile range). Other results are reported as means $\pm \mathrm{SD}$. A $p$ value of $\leq 0.05$ was considered significant for all analyses, which were performed using JMP 4.0 software (SAS Institute, Cary, NC, USA).

Variables were compared between groups using twotailed unpaired $t$ tests, except for proportions of IGT and metabolic syndrome, which were compared using twotailed Fisher's exact tests. In Table 1, data from PCOS index women are provided in order to illustrate the characteristics of our population and no statistical comparison with the other groups was made. Only available data obtained while the women were not under oral contraceptive, anti-androgen or insulin-sensitising treatments are reported.

Since potential differences in age or obesity might affect the results, each variable difference between groups was adjusted for age and BMI using multiple linear regression analyses. These adjusted $p$ values are reported in Table 1 . Of note, due to our sample size no more than two or three co-variables could be included in this model (i.e. a maximum of four or five parameters, including the intercept and group status, for a total of 45 participants). Moreover, it has been previously shown in PCOS women that obesity (i.e. BMI status) was a significant modifier of the relationship between PCOS status and many metabolic parameters [8, 35]. Thus, we performed multiple linear regression analyses for all variables in Table 1 with group status, BMI status and the interaction between group status and BMI status as independent parameters. BMI status was based on median of BMI for all participants, i.e. BMI $\leq 26.5 \mathrm{~kg} / \mathrm{m}^{2}$ or BMI $>26.5 \mathrm{~kg} / \mathrm{m}^{2}$. As mentioned in the footnotes of Table 1, the adjusted $p$ value should be interpreted with caution when there is a significant interaction, which means that obesity is a significant modifier of the relationship between group status and the dependent variable of Table 1. To appropriately assess significant interactions, subgroup analyses by BMI status were performed and are reported in Table 2, as well as age and BMI. It is not 
Table 1 Clinical and biochemical characteristics of brothers of women with PCOS, male control participants and PCOS index women

\begin{tabular}{|c|c|c|c|c|c|}
\hline Characteristics & $\begin{array}{l}\text { Brothers } \\
(n=17)\end{array}$ & $\begin{array}{l}\text { Male control participants } \\
(n=28)\end{array}$ & $p$ value $^{\mathrm{a}}$ & $\begin{array}{l}\text { Adjusted } \\
p \text { value }^{\mathrm{b}}\end{array}$ & $\begin{array}{l}\text { PCOS index sisters } \\
(n=13)\end{array}$ \\
\hline Age (years) & $31 \pm 9$ & $29 \pm 7$ & 0.42 & - & $29 \pm 6$ \\
\hline BMI $\left(\mathrm{kg} / \mathrm{m}^{2}\right)$ & $27.6 \pm 3.7$ & $25.9 \pm 3.9$ & 0.14 & - & $36.4 \pm 8.1$ \\
\hline Waist circumference $(\mathrm{cm})$ & $92 \pm 12$ & $88 \pm 11$ & 0.24 & 0.93 & - \\
\hline Fat $\%$ & $23.8 \pm 5.8$ & $20.7 \pm 6.7$ & 0.13 & 0.71 & - \\
\hline Systolic BP (mmHg) & $124 \pm 19$ & $120 \pm 13$ & 0.50 & 0.86 & $127 \pm 15$ \\
\hline Diastolic BP (mmHg) & $74 \pm 12$ & $68 \pm 10$ & 0.06 & 0.19 & $84 \pm 10$ \\
\hline Total testosterone $(\mathrm{nmol} / \mathrm{l})$ & $16.3 \pm 5.8$ & $19.2 \pm 5.5$ & 0.10 & 0.26 & $3.6 \pm 1.2$ \\
\hline SHBG $(\mathrm{nmol} / \mathrm{l})$ & $21.7 \pm 12$ & $25.7 \pm 9$ & 0.20 & $0.47^{\mathrm{c}}$ & $26.5 \pm 14.7$ \\
\hline Calculated free testosterone $(\mathrm{pmol} / \mathrm{l})^{\mathrm{d}}$ & $478 \pm 218$ & $531 \pm 207$ & 0.42 & 0.56 & $89 \pm 36$ \\
\hline Androstenedione (nmol/1) & $5.5 \pm 2.2$ & $6.2 \pm 1.8$ & 0.29 & $0.73^{\mathrm{c}}$ & - \\
\hline DHEAS $(\mu \mathrm{mol} / 1)^{\mathrm{e}}$ & $7.2(4.1-11.0)$ & $7.1(5.3-9.3)$ & 0.93 & 0.61 & - \\
\hline Triacylglycerol $(\mathrm{mmol} / \mathrm{l})^{\mathrm{e}}$ & $1.66(0.94-2.64)$ & $0.99(0.70-1.32)$ & 0.02 & 0.08 & $1.29(0.75-1.95)$ \\
\hline HDL-cholesterol (mmol/l) & $1.15 \pm 0.34$ & $1.24 \pm 0.25$ & 0.33 & 0.53 & $1.32 \pm 0.45$ \\
\hline LDL-cholesterol (mmol/l) & $2.99 \pm 0.78$ & $2.87 \pm 1.06$ & 0.71 & 0.84 & $3.10 \pm 0.83$ \\
\hline Total cholesterol:HDL-cholesterol ratio ${ }^{\mathrm{e}}$ & $4.5(3.6-5.2)$ & $3.7(2.8-4.7)$ & 0.09 & 0.35 & $4.0(2.9-5.6)$ \\
\hline $\operatorname{hsCRP}(g / l)^{\mathrm{e}}$ & $0.84(0.51-1.20)$ & $0.69(0.27-1.53)$ & 0.59 & 0.86 & - \\
\hline PAI-1 (IU/1) $)^{\mathrm{e}}$ & $27(15-42)$ & $16(10-28)$ & 0.02 & $0.06^{\mathrm{c}}$ & - \\
\hline Fibrinogen $(\mu \mathrm{mol} / \mathrm{l})$ & $8.8 \pm 1.9$ & $8.3 \pm 1.5$ & 0.36 & $0.73^{\mathrm{c}}$ & - \\
\hline Factor VIII $(\mathrm{g} / \mathrm{l})^{\mathrm{e}}$ & $1.32(1.04-1.62)$ & $1.08(0.92-1.25)$ & 0.02 & 0.01 & - \\
\hline Fasting glucose (mmol/l) & $5.14 \pm 0.30$ & $4.70 \pm 0.67$ & 0.02 & 0.06 & $4.97 \pm 0.75$ \\
\hline $2 \mathrm{~h}$ glucose (OGTT; mmol/l) & $6.64 \pm 1.08$ & $4.54 \pm 1.27$ & $<0.001$ & $<0.001$ & $6.69 \pm 2.45$ \\
\hline $\operatorname{AUC}_{\text {glucose }}(\mathrm{mmol} / 1 \times \min )$ & $961 \pm 151$ & $781 \pm 139$ & $<0.001$ & $<0.001$ & - \\
\hline Glucose intolerance $(\%)$ & 17.6 & 0 & 0.05 & - & 15.4 \\
\hline Metabolic syndrome (\%) & 17.6 & 7.1 & 0.35 & - & 61.5 \\
\hline Fasting insulin $(\mathrm{pmol} / 1)^{\mathrm{e}}$ & $60(37-90)$ & $49(32-56)$ & 0.28 & 0.54 & - \\
\hline $\operatorname{AUC}_{\text {insulin }}(\mathrm{nmol} / 1 \times \min )^{\mathrm{e}}$ & $61.5(33.1-101.6)$ & $32.7(22.0-47.3)$ & $<0.001$ & $0.001^{\mathrm{c}}$ & - \\
\hline$M$ value $\left(\mu \mathrm{mol} \mathrm{kg}-1 \mathrm{~min}^{-1}\right)$ & $28.2 \pm 11.4$ & $45.4 \pm 15.2$ & $<0.001$ & $<0.001$ & - \\
\hline
\end{tabular}

Results are expressed as means $\pm \mathrm{SD}$, unless indicated otherwise. To convert values for total testosterone to ng/dl, divide by 0.0347 ; for SHBG to $\mu \mathrm{g} / \mathrm{dl}$, divide by 34.7 ; for free testosterone to $\mathrm{ng} / \mathrm{dl}$, divide by 34.7 ; for androstenedione to $\mathrm{ng} / \mathrm{ml}$, divide by 3.492 ; for DHEAS to $\mu \mathrm{g} / \mathrm{dl}$, divide by 0.027; for triacylglycerol to $\mathrm{mg} / \mathrm{dl}$, divide by 0.0113 ; for cholesterol to $\mathrm{mg} / \mathrm{dl}$, divide by 0.0259 ; for glucose to $\mathrm{mg} / \mathrm{dl}$, divide by 0.0556 ; and for insulin to $\mu \mathrm{IU} / \mathrm{ml}$, divide by 6.945 . The normal ranges for ovulatory women are as follows: total testosterone $<2.4 \mathrm{nmol} / 1$; SHBG $>22 \mathrm{nmol} / \mathrm{l}$; and calculated free testosterone $<50 \mathrm{pmol} / 1$

Fat $\%$ percentage total fat mass by bioimpedance

${ }^{a}$ Two-tailed unpaired $t$ tests, except for proportions of glucose intolerance and the metabolic syndrome, which were compared using two-tailed Fisher's exact tests

${ }^{\mathrm{b}}$ Adjustment for age and BMI (as continuous variables)

${ }^{\mathrm{c}} p$ value should be interpreted with caution because there was a significant interaction between group status and BMI status (BMI $\leq 26.5 \mathrm{~kg} / \mathrm{m}^{2}$ or $>26.5 \mathrm{~kg} / \mathrm{m}^{2}$, based on the median of BMI for all participants); please see Table 2 for appropriate analyses following this interaction

${ }^{\mathrm{d}}$ Free testosterone was calculated by the method of Sodergard et al. [31]

${ }^{\mathrm{e}} \log _{\mathrm{e}}$-transformed for analyses and results are expressed as geometrical means with interquartile ranges

pertinent to perform subgroup analyses for other variables because the absence of interaction indicates no significant modifying effect of BMI status. Due to reduced power of such analyses, results could be misinterpreted.

When planning the study, we determined that 19 participants per group would give our study $85 \%$ power to detect the same difference in insulin sensitivity as the difference observed between healthy male participants with or without at least two first-degree relatives with type 2 diabetes [36]. This previously published study used the same clamp technique as ours and we expected that the degree of insulin resistance in PCOS brothers would be at least as high as in this high-risk population. The power calculation of our study based on 28 control individuals and 17 brothers and using the same data was $88 \%$.

\section{Results}

Clinical characteristics and levels of sex steroids The clinical characteristics of the 17 brothers of women with PCOS and 28 male control participants are presented in Table 1. All participants were white of European origin. Age, BMI, waist circumference and total fat percentage were comparable between groups. Systolic BPs were similar, but diastolic BPs tended to be increased in brothers, although not quite 
Table 2 Subgroup analyses by two strata of BMI for variables with significant interaction between brother status and BMI status, as well as age and BMI

\begin{tabular}{|c|c|c|c|c|c|c|}
\hline \multirow[t]{2}{*}{ Characteristics } & \multicolumn{3}{|l|}{$\mathrm{BMI} \leq 26.5 \mathrm{~kg} / \mathrm{m}^{2}$} & \multicolumn{3}{|l|}{$\mathrm{BMI}>26.5 \mathrm{~kg} / \mathrm{m}^{2}$} \\
\hline & $\begin{array}{l}\text { Brothers } \\
(n=7)\end{array}$ & $\begin{array}{l}\text { Male control } \\
\text { participants }(n=15)\end{array}$ & $p$ value $^{\mathrm{a}}$ & $\begin{array}{l}\text { Brothers } \\
(n=10)\end{array}$ & $\begin{array}{l}\text { Male control } \\
\text { participants }(n=13)\end{array}$ & $p$ value $^{\mathrm{a}}$ \\
\hline Age (years) & $26 \pm 8$ & $28 \pm 7$ & 0.61 & $34 \pm 9$ & $30 \pm 7$ & 0.23 \\
\hline BMI $\left(\mathrm{kg} / \mathrm{m}^{2}\right)$ & $24.2 \pm 1.8$ & $23.1 \pm 1.9$ & 0.20 & $30.0 \pm 2.5$ & $29.1 \pm 2.8$ & 0.45 \\
\hline SHBG (nmol/l) & $31.6 \pm 9.3$ & $25.3 \pm 7.2$ & 0.09 & $14.8 \pm 8.4$ & $26.2 \pm 10.2$ & 0.01 \\
\hline Androstenedione (nmol/1) & $7.1 \pm 2.5$ & $6.3 \pm 2.1$ & 0.42 & $4.4 \pm 1.1$ & $6.0 \pm 1.5$ & 0.01 \\
\hline PAI-1 (IU/1) ${ }^{\mathrm{b}}$ & $18(15-26)$ & $18(11-33)$ & 0.91 & $36(25-66)$ & $13(6-27)$ & 0.01 \\
\hline Fibrinogen $(\mu \mathrm{mol} / \mathrm{l})$ & $7.6 \pm 0.2$ & $8.4 \pm 1.7$ & 0.25 & $9.6 \pm 2.1$ & $8.2 \pm 1.3$ & 0.06 \\
\hline $\operatorname{AUC}_{\text {insulin }}(\mathrm{nmol} / 1 \times \min )^{\mathrm{b}}$ & $35.0(29.5-36.8)$ & $34.3(25.3-44.1)$ & 0.90 & $91.3(72.7-117)$ & $30.9(21.1-51.6)$ & $<0.001$ \\
\hline
\end{tabular}

Results are expressed as means $\pm \mathrm{SD}$, unless indicated otherwise

${ }^{\text {a }}$ Two-tailed unpaired $t$ tests

${ }^{\mathrm{b}} \mathrm{Log}_{\mathrm{e}}$-transformed for analyses and results are expressed as geometrical means with interquartile ranges

significantly $(p=0.06)$. Three brothers reported a history of type 2 diabetes in first-degree relatives vs one in the control group ( $18 \%$ vs $4 \%, p=0.14)$.

Free testosterone levels were comparable between groups, but there was a trend for lower SHBG levels in brothers, and consequently lower total testosterone levels ( $p=0.16$ and $p=0.13$ for SHBG and total testosterone, respectively). Androstenedione and DHEAS were also similar in both groups. Finally, female index cases with PCOS were obese on average (BMI $>30 \mathrm{~kg} / \mathrm{m}^{2}$ ) and had higher diastolic BP than both brothers and control participants. As expected, their total and free testosterone levels were higher than the upper limit of normality for our laboratory $(2.4 \mathrm{nmol} / 1[70 \mathrm{ng} / \mathrm{dl}]$ and $50 \mathrm{pmol} / \mathrm{l}[1.4 \mathrm{ng} / \mathrm{dl}]$, respectively).

Metabolic measurements, insulin sensitivity and total-body carbohydrate metabolism Fasting triacylglycerol levels were significantly increased in brothers compared with control participants $(p=0.02)$, with borderline increased ratios of total cholesterol to HDL-cholesterol $(p=0.09$; Table 1 and Fig. 1). However, HDL-cholesterol and LDLcholesterol levels were comparable. hsCRP was not increased in brothers. With regard to prothrombotic factors, PAI-1 $(p=0.02)$ and factor VIII $(p=0.02)$ were significantly increased in brothers compared with control individuals, but not fibrinogen. Interestingly, fasting glucose levels as well as $2 \mathrm{~h}$ glucose levels and the $\mathrm{AUC}_{\text {glucose }}$ during the OGTT were all significantly increased in brothers $(p=0.02$, $p<0.001$ and $p<0.001$, respectively), indicating decreased glucose tolerance. Three (18\%) brothers had IGT as opposed to no control participants $(p=0.05)$. Only one of these three brothers reported having a first-degree relative with type 2 diabetes. The proportion of metabolic syndrome, as defined by the US National Cholesterol Educa- tion Program Adult Treatment Panel III (NCEP-ATP III) guidelines [37], was more than doubled in brothers compared with control participants (18 vs $7 \%$ ), but this difference was not statistically significant.

Sisters with PCOS had higher levels of triacylglycerol, fasting glucose and $2 \mathrm{~h}$ glucose during the OGTT than male control individuals, but in ranges comparable with their brothers. However, the proportion with metabolic syndrome (61\%), as defined by NCEP-ATP III, was much higher in sisters than both control participants and brothers. As expected in females, women had higher HDL-cholesterol than male control individuals and brothers. Finally, $14 \%$ of PCOS sisters had abnormal glucose tolerance.

Fasting insulin levels were increased in brothers, although not significantly, but $\mathrm{AUC}_{\text {insulin }}$ was almost doubled compared with control participants $(p<0.001)$. Insulin sensi-

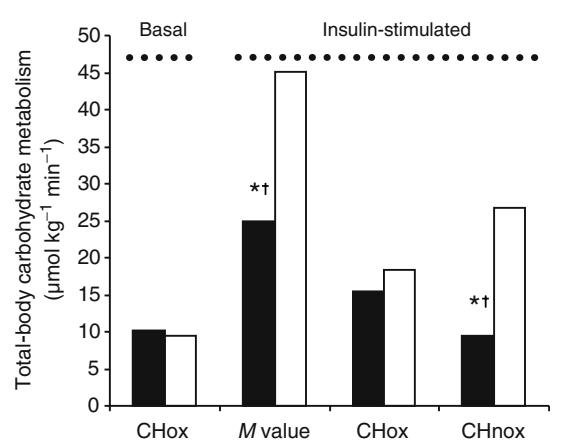

Fig. 1 Total-body carbohydrate metabolism, as determined by indirect calorimetry, in unselected subgroups of brothers of women with PCOS and male control participants. Closed bars, brothers; open bars, male controls. ${ }^{*} p<0.001$ vs male controls (two-tailed $t$ tests); $\dagger p \leq 0.001$ vs male controls after adjustment for age and BMI (multiple linear regression analyses); no significant interaction between BMI status and group status was found 
tivity ( $M$ value) was significantly decreased by $38 \%$ in brothers of PCOS women compared with male control individuals $(p<0.001)$. Finally, basal and insulin-stimulated CHox were not significantly different in this subgroup of brothers $(n=13)$ compared with a subgroup of control participants $(n=22$; Fig. 1). However, insulin-stimulated CHnox was significantly decreased by $65 \%$ in brothers compared with control individuals $(p<0.001)$.

Adjustments for age and BMI All variable differences between groups presented in Table 1 were adjusted for age and BMI using multiple linear regression analyses. Resulting partial $p$ values for the group status effect are reported as 'adjusted $p$ values' (Table 1 and Fig. 1). After these adjustments, levels of factor VIII $(p=0.01)$ and $2 \mathrm{~h}$ glucose $(p<0.001)$, as well as $\mathrm{AUC}_{\text {glucose }}$ and $\mathrm{AUC}_{\text {insulin }}$ during the OGTT $(p<0.001$ and $p=0.001$, respectively), were still significantly different between the two groups, but differences in triacylglycerol, PAI-1 and fasting glucose levels were no longer significant $(p=0.08, p=0.06$ and $p=0.06$, respectively). However, non-significant results for SHBG, androstenedione, PAI-1 and fibrinogen levels, as well as significant result for $\mathrm{AUC}_{\text {insulin, }}$ should be interpreted with caution due to interactions between BMI status and group status (see following section). Insulin sensitivity and $\mathrm{CHnox}$ were also significantly reduced in brothers compared with control individuals after adjustment $(p<0.001$ and $p=0.003$, respectively; Table 1 and Fig. 1). Significant interactions found during these analyses are reported in Table 1 (see footnotes) and were subjected to subgroup analyses based on BMI status (see below).

Subgroup analyses based on BMI status Subgroup analyses were performed for all variables that demonstrated significant interactions between BMI status and group status following multiple linear models (Table 2). These tests were stratified according to the median for BMI $(\leq$ or $>26.5 \mathrm{~kg} / \mathrm{m}^{2}$ ) in all participants. The subgroup with a BMI $\leq 26.5 \mathrm{~kg} / \mathrm{m}^{2}$ included seven brothers and 15 control participants, and the one with BMI $>26.5 \mathrm{~kg} / \mathrm{m}^{2}$ comprised ten brothers and 13 control participants. As shown in Table 2, ages and BMIs were quite close between brothers and control participants in both BMI strata. However, PAI-1 and $\mathrm{AUC}_{\text {insulin }}$ were significantly increased and SHBG and androstenedione significantly decreased only in brothers from the obese group (vs obese control individuals). Fibrinogen levels tended to be higher in obese brothers compared with obese control participants, although this was not significant. There was no such trend in non-obese participants.

Post hoc analyses To ensure that PCOS brothers with IGT or family history of type 2 diabetes (first-degree) were not driving our results, we excluded the five brothers with these characteristics, as well as the one male control individual who had a positive family history, and repeated all analyses. The conclusions were unchanged, except for higher levels of triacylglycerol and PAI-1 that were no longer significant (data not shown). Importantly, differences in fasting glucose, $2 \mathrm{~h}$ glucose, $\mathrm{AUC}_{\text {glucose }}, \mathrm{AUC}_{\text {insulin }}, M$ value and $\mathrm{CHnox}$ persisted after excluding these six participants, even after adjustment for age, BMI and the interaction between BMI and group status (adjusted $p=0.02,<0.001,<0.004$, $<0.02,<0.02$ and $<0.02$, respectively; no significant interaction; data not shown). Following these post hoc analyses, interactions persisted only for factor VIII and $\mathrm{AUC}_{\text {insulin. }}$. Similarly, the conclusions were identical when all analyses were repeated after averaging the results of two brothers of the same family (only one pair of brothers).

\section{Discussion}

The aim of this study was to test the hypothesis that male siblings of women with PCOS exhibit insulin resistance and altered metabolic parameters independently of obesity, as already described in PCOS. We found that brothers of women with PCOS had a $38 \%$ decrease in insulin sensitivity ( $M$ value) associated with decreased tolerance to glucose, hypertriacylglycerolaemia, hypercoagulability (increased PAI-1 and factor VIII levels) and post-glucose challenge hyperinsulinaemia compared with male control individuals with similar anthropometric parameters on average. Furthermore, indirect calorimetry performed in a subgroup of the participants demonstrated that insulinstimulated glucose disposal ( $M$ value) was primarily altered in its non-oxidative metabolism, which was decreased by $65 \%$ in brothers. These abnormalities persisted even when corrected for subtle differences in age and BMI between the brothers and male control participants, except for triacylglycerol. Therefore, we demonstrated that brothers of women with PCOS display insulin resistance, glucose intolerance and many anomalies characteristic of the insulin resistance syndrome.

Multiple linear regression analyses also provided evidence for significant modifying effects of obesity. Indeed, SHBG, PAI-1 and glucose-stimulated insulin levels were mainly altered in obese brothers, compared with obese control participants. These results suggest a synergistic effect of heredity and acquired obesity for the development of the observed metabolic abnormalities. Lower androstenedione levels in obese brothers suggest that higher insulin resistance and hyperinsulinaemia associated with obesity might cause a decrease in androgen production in men. The absence of interaction for all other variables demonstrates that brothers are characterised by metabolic anomalies regardless of obesity. 
Another major and novel finding of the present study is that glucose intolerance, which results from relative beta cell dysfunction [38], is manifest in brothers of women with PCOS irrespectively of the degree of obesity. Only one previous study reported on glucose tolerance during OGTT in brothers of PCOS women and did not find a significant alteration [22]. One could argue that this discrepancy might be explained by more prominent beta cell dysfunction in the index women with PCOS, due to selection biases for example. But the proportion of abnormal glucose tolerance in proband women with PCOS in our study (15\%) was not high compared with published data (>16\%) [3].

It has been shown that approximately $50 \%$ of sisters of women with PCOS are affected by hyperandrogenaemia and/or polycystic ovaries [11-13], suggesting that this disorder is highly inherited. Because of the potential role of insulin resistance or insulin action in the pathophysiology of PCOS, it is possible that the apparent inheritance of this syndrome reflects a familial predisposition to develop insulin resistance. This is the rationale for assessing brothers of women with PCOS in order to determine if they are also affected by abnormal insulin action.

To the best of our knowledge, nine studies have previously assessed the metabolic phenotypes of relatives of women with PCOS [13, 19-25, 39]. The first of these studies concluded that glucose-stimulated hyperinsulinaemia was frequent in sisters $(n=24)$ and brothers $(n=5)$ of PCOS probands [19]. A large study by Legro et al. [13] confirmed that fasting insulin levels were elevated in 307 sisters of PCOS women, compared with 47 control participants. Two other studies $[20,22]$ have also found that sisters and brothers of women with PCOS have significantly higher insulin levels (fasting or during OGTT) and homeostasis model assessment insulin resistance compared with control individuals. Finally, a recent study demonstrated that sisters of PCOS women have increased prevalence of the metabolic syndrome [24].

Only one small study, to the best of our knowledge, has directly measured insulin sensitivity. This study [21] used a short insulin tolerance test in a small high-risk population from India and demonstrated decreased insulin sensitivity in non-diabetic brothers $(n=10)$ of PCOS women compared with non-diabetic male control participants $(n=10)$. Notably, insulin tolerance tests are not recognised as 'gold standard' methods to measure insulin sensitivity [28]. Our study is the first to show impaired total-body insulin sensitivity and insulin-stimulated non-oxidative glucose metabolism in brothers of women with PCOS women independently of a difference in obesity using a euglycaemic-hyperinsulinaemic clamp and appropriate control participants.

Similar alterations of insulin sensitivity and non-oxidative glucose metabolism, with preservation of oxidative metab- olism, have also been described in glucose-tolerant firstdegree relatives of patients with type 2 diabetes [40]. Our results are also comparable with the findings of reduced insulin sensitivity without evidence of inflammation (normal levels of hsCRP) in non-obese participants with two relatives with type 2 diabetes or one relative plus a personal history of gestational diabetes, compared with control individuals[41]. It has been estimated that $51 \%$ of participants with one first-degree relative affected with type 2 diabetes [42], and $76 \%$ of those with two affected firstdegree relatives [43], will ultimately develop type 2 diabetes. Thus, even if $82 \%$ of our brothers of PCOS women did not have a first-degree relative with type 2 diabetes, our results showed that they display early metabolic defects similar to those individuals at very high risk of developing type 2 diabetes.

Although our main conclusions are supported by highly significant results and robust statistical analyses, our study design has some limitations that should be discussed. First, this is not a genetic or family study. Due to the complexity of clamp studies, it was not possible to assess all members of affected and non-affected families. Only volunteers could be studied. Thus, the sample size was more limited than in family studies and control participants were recruited based on a convenient sampling. Accordingly, control participants are not necessarily representative of the general male population of this age and population prevalence cannot be determined. Furthermore, inference from the brothers' group to all PCOS brothers might be less robust in the context of a smaller sample size. However, age and BMI were similar in both groups, and the results were highly significant due to the use of precise measures (clamp studies), which are strengths of this study.

Another limitation of our study is the absence of IGT and only one participant with a first-degree family history of type 2 diabetes in our control group. IGT is relatively rare in this age group (7.8\% in NHANES II [3]), but we might have unintentionally selected healthier control individuals than expected. In order to assess the impact of these findings on our conclusions, we excluded participants with IGT (three brothers) or with siblings affected by type 2 diabetes (two more brothers and one control individual). These analyses did not change remarkably the results compared with analyses performed in the total group of participants. These post hoc analyses underscore the robustness of our conclusions. Finally, we did not seek the presence of type 2 diabetes in second-degree relatives of our male control participants. Thus, it is not possible to assess the impact of this more distant genetic risk factor for metabolic disorders.

In conclusion, we demonstrated that brothers of women with PCOS are characterised by reduced insulin sensitivity, decreased glucose tolerance and dyscoagulability independent- 
ly of the degree of obesity compared with control participants. Therefore, brothers of PCOS women may have inherited the insulin resistance and metabolic syndrome typical of PCOS. Finally, we defined a new and clinically relevant model for research on the physiological causes of insulin resistance and early steps in the development of type 2 diabetes. Extrapolating from the risk conferred by insulin resistance in other populations, our results suggest that first-degree male relatives of women with PCOS may have a very high risk of developing type 2 diabetes and related metabolic disorders. Follow-up studies to determine the proportion of brothers who develop type 2 diabetes would be highly desirable.

Acknowledgement This work was supported in part by the Fonds de la Recherche en Santé du Québec (FRSQ; Quebec Health Research Funds; J.-P. Baillargeon, no. 2834) and the Canadian Institutes for Health Research (CIHR; A. C. Carpentier, no. MOP 53094). The Centre de Recherche Etienne-Le Bel is an FRSQ-funded research centre. J.-P. Baillargeon is a Junior 2 Clinical Investigator of the FRSQ and A. C. Carpentier is a Junior 2 Investigator of the FRSQ.

Duality of interest The authors declare that there is no duality of interest associated with this manuscript.

\section{References}

1. The Rotterdam ESHRE/ASRM-sponsored PCOS consensus workshop group (2004) Revised 2003 consensus on diagnostic criteria and long-term health risks related to polycystic ovary syndrome (PCOS). Hum Reprod 19:41-47

2. Zawadsky JK, Dunaif A (1992) Diagnostic criteria for polycystic ovary syndrome: towards a rational approach. In: Dunaif A, Givens JR, Haseltine FP, Merriam GR (eds) Current issues in endocrinology and metabolism: polycystic ovary syndrome. Blackwell, Cambridge, pp 377-384

3. Baillargeon JP (2005) Use of insulin sensitizers in polycystic ovarian syndrome. Curr Opin Investig Drugs 6:1012-1022

4. Baillargeon JP, Iuorno MJ, Nestler JE (2003) Insulin sensitizers for polycystic ovary syndrome. Clin Obstet Gynecol 46:325-340

5. Glueck CJ, Papanna R, Wang P, Goldenberg N, Sieve-Smith L (2003) Incidence and treatment of metabolic syndrome in newly referred women with confirmed polycystic ovarian syndrome. Metabolism 52:908-915

6. Cibula D, Cifkova R, Fanta M, Poledne R, Zivny J, Skibova J (2000) Increased risk of non-insulin dependent diabetes mellitus, arterial hypertension and coronary artery disease in perimenopausal women with a history of the polycystic ovary syndrome. Hum Reprod 15:785-789

7. Nestler JE (1997) Role of hyperinsulinemia in the pathogenesis of the polycystic ovary syndrome, and its clinical implications. Semin Reprod Endocrinol 15:111-122

8. Dunaif A, Segal KR, Futterweit W, Dobrjansky A (1989) Profound peripheral insulin resistance, independent of obesity, in polycystic ovary syndrome. Diabetes $38: 1165-1174$

9. Iuorno MJ, Jakubowicz DJ, Baillargeon JP et al (2002) Effects of D-chiro-inositol in lean women with the polycystic ovary syndrome. Endocr Pract 8:417-423

10. Nestler JE, Jakubowicz DJ, Reamer P, Gunn RD, Allan G (1999) Ovulatory and metabolic effects of D-chiro-inositol in the polycystic ovary syndrome. N Engl J Med 340:1314-1320
11. Franks S, Gharani N, Waterworth D et al (1997) The genetic basis of polycystic ovary syndrome. Hum Reprod 12:2641-2648

12. Legro RS, Driscoll D, Strauss JF, Fox J, Dunaif A (1998) Evidence for a genetic basis for hyperandrogenemia in polycystic ovary syndrome. Proc Natl Acad Sci U S A 95:14956-14960

13. Legro RS, Bentley-Lewis R, Driscoll D, Wang SC, Dunaif A (2002) Insulin resistance in the sisters of women with polycystic ovary syndrome: association with hyperandrogenemia rather than menstrual irregularity. J Clin Endocrinol Metab 87:2128-2133

14. Ferriman D, Purdie AW (1979) The inheritance of polycystic ovarian disease and a possible relationship to premature balding. Clin Endocrinol (Oxf) 11:291-300

15. Carey AH, Chan KL, Short F, White D, Williamson R, Franks S (1993) Evidence for a single gene effect causing polycystic ovaries and male pattern baldness. Clin Endocrinol (Oxf) 38:653-658

16. Govind A, Obhrai MS, Clayton RN (1999) Polycystic ovaries are inherited as an autosomal dominant trait: analysis of 29 polycystic ovary syndrome and 10 control families. J Clin Endocrinol Metab 84:38-43

17. Mao W, Li M, Chen Y et al (2001) Study on the mode of inheritance for familial polycystic ovary syndrome. Chung-Hua i Hsueh i Chuan Hsueh Tsa Chih 18:21-23 (article in Chinese)

18. Legro RS, Kunselman AR, Demers L, Wang SC, Bentley-Lewis R, Dunaif A (2002) Elevated dehydroepiandrosterone sulfate levels as the reproductive phenotype in the brothers of women with polycystic ovary syndrome. J Clin Endocrinol Metab 87:2134-2138

19. Norman RJ, Masters S, Hague W (1996) Hyperinsulinemia is common in family members of women with polycystic ovary syndrome. Fertil Steril 66:942-947

20. Yildiz BO, Yarali H, Oguz H, Bayraktar M (2003) Glucose intolerance, insulin resistance, and hyperandrogenemia in first degree relatives of women with polycystic ovary syndrome. J Clin Endocrinol Metab 88:2031-2036

21. Kaushal R, Parchure N, Bano G, Kaski JC, Nussey SS (2004) Insulin resistance and endothelial dysfunction in the brothers of Indian subcontinent Asian women with polycystic ovaries. Clin Endocrinol (Oxf) 60:322-328

22. Yilmaz M, Bukan N, Ersoy R et al (2005) Glucose intolerance, insulin resistance and cardiovascular risk factors in first degree relatives of women with polycystic ovary syndrome. Hum Reprod 20:2414-2420

23. Sir-Petermann T, Angel B, Maliqueo M, Carvajal F, Santos JL, Perez-Bravo F (2002) Prevalence of type II diabetes mellitus and insulin resistance in parents of women with polycystic ovary syndrome. Diabetologia 45:959-964

24. Sam S, Legro RS, Bentley-Lewis R, Dunaif A (2005) Dyslipidemia and metabolic syndrome in the sisters of women with polycystic ovary syndrome. J Clin Endocrinol Metab 90:4797-4802

25. Leibel NI, Baumann EE, Kocherginsky M, Rosenfield RL (2006) Relationship of adolescent polycystic ovary syndrome to parental metabolic syndrome. J Clin Endocrinol Metab 91:1275-1283

26. Azziz R, Dewailly D, Owerbach D (1994) Nonclassic adrenal hyperplasia: current concepts. J Clin Endocrinol Metab 78:810-815

27. Carpentier AC, Frisch F, Cyr D et al (2005) On the suppression of plasma nonesterified fatty acids by insulin during enhanced intravascular lipolysis in humans. Am J Physiol Endocrinol Metab 289:E849-E856

28. DeFronzo RA, Tobin JD, Andres R (1979) Glucose clamp technique: a method for quantifying insulin secretion and resistance. Am J Physiol 237:E214-E223

29. Carpentier A, Patterson BW, Uffelman KD et al (2001) The effect of systemic versus portal insulin delivery in pancreas transplantation on insulin action and VLDL metabolism. Diabetes 50: $1402-1413$

30. Frayn KN (1983) Calculation of substrate oxidation rates in vivo from gaseous exchange. J Appl Physiol 55:628-634 
31. Sodergard R, Backstrom T, Shanbhag V, Carstensen H (1982) Calculation of free and bound fractions of testosterone and estradiol-17 beta to human plasma proteins at body temperature. J Steroid Biochem 16:801-810

32. Friedewald WT, Levy RI, Fredrickson DS (1972) Estimation of the concentration of low-density lipoprotein cholesterol in plasma, without use of the preparative ultracentrifuge. Clin Chem 18:499-502

33. Devaraj S, Rosenson RS, Jialal I (2004) Metabolic syndrome: an appraisal of the pro-inflammatory and procoagulant status. Endocrinol Metab Clin North Am 33:431-453

34. Wannamethee SG, Lowe GD, Shaper AG, Rumley A, Lennon L, Whincup PH (2005) The metabolic syndrome and insulin resistance: relationship to haemostatic and inflammatory markers in older non-diabetic men. Atherosclerosis 181:101-108

35. Legro RS, Kunselman AR, Dodson WC, Dunaif A (1999) Prevalence and predictors of risk for type 2 diabetes mellitus and impaired glucose tolerance in polycystic ovary syndrome: a prospective, controlled study in 254 affected women. J Clin Endocrinol Metab 84:165-169

36. Johanson EH, Jansson PA, Lonn L et al (2003) Fat distribution, lipid accumulation in the liver, and exercise capacity do not explain the insulin resistance in healthy males with a family history for type 2 diabetes. J Clin Endocrinol Metab 88:4232-4238

37. Executive Summary of The Third Report of The National Cholesterol Education Program (NCEP) (2001) Expert panel on detection, evaluation, and treatment of high blood cholesterol in adults (Adult Treatment Panel III). JAMA 285:2486-2497

38. Bergman RN, Finegood DT, Kahn SE (2002) The evolution of beta-cell dysfunction and insulin resistance in type 2 diabetes. Eur J Clin Invest 32(Suppl 3):35-45

39. Colilla S, Cox NJ, Ehrmann DA (2001) Heritability of insulin secretion and insulin action in women with polycystic ovary syndrome and their first degree relatives. J Clin Endocrinol Metab 86:2027-2031

40. Eriksson J, Franssila-Kallunki A, Ekstrand A et al (1989) Early metabolic defects in persons at increased risk for non-insulindependent diabetes mellitus. N Engl J Med 321:337-343

41. Kriketos AD, Greenfield JR, Peake PW et al (2004) Inflammation, insulin resistance, and adiposity: a study of first-degree relatives of type 2 diabetic subjects. Diabetes Care 27:2033-2040

42. Nauck MA, Meier JJ, Wolfersdorff AV, Tillil H, Creutzfeldt W, Kobberling J (2003) A 25-year follow-up study of glucose tolerance in first-degree relatives of type 2 diabetic patients: association of impaired or diabetic glucose tolerance with other components of the metabolic syndrome. Acta Diabetol 40: $163-172$

43. Martin BC, Warram JH, Krolewski AS, Bergman RN, Soeldner JS, Kahn CR (1992) Role of glucose and insulin resistance in development of type 2 diabetes mellitus: results of a 25 -year follow-up study. Lancet 340:925-929 